\title{
Rádios Comunitárias: Necessidade de se reinventar
}

\section{Community Radios: Need to reinvent themselves}

DOI: $10.46814 / \operatorname{lajdv3n6-021}$

Recebimento dos originais: 01/11/2021

Aceitação para publicação: 14/12/2021

Bruno Araújo Torres

Formado em Comunicação Social com habilitação em Publicidade e Propaganda na Universidade de Ribeirão Preto, SP.

Doutor em Comunicación Audiovisual pela Universidade de Valencia, Espanha.

Título revalidado pela Universidade Federal do Rio Grande do Sul como Doutor em Comunicação e Informação;

E-mail: btorresbr@hotmail.com

\section{RESUMO}

Embora seja um tema muito comentado na nossa atualidade, o tema das rádios comunitárias ainda é pouco estudado dentro da sua devida importância na comunicação científica. Abordando de maneira sucinta as novas tecnologias, o presente trabalho pretende ampliar o debate sobre o tema das rádios comunitárias no brasil na atual conjuntura político, econômica e social do país. Verifica-se uma necessidade de criar uma nova maneira de se fazer rádio para as comunidades.

Palavras-chave: rádio, rádio comunitária, programação.

\begin{abstract}
Although it is a much talked about theme in our present time, the theme of community radios is still little studied within its due importance in scientific communication. By briefly addressing the new technologies, this paper intends to broaden the debate on the subject of community radios in brazil in the current political, economic and social situation of the country. There is a need to create a new way of doing radio for the communities.
\end{abstract}

Keywords: radio, community radio, programming.

\section{INTRODUÇÃO}

Passados mais de dez anos da lei que regulamentou o serviço de radiodifusão comunitária no Brasil, passamos, em 2010, de mais de quatro mil emissoras comunitárias legalizadas ${ }^{1}$. Essas emissoras, que foram criadas com um objetivo bem específico, mais parecem ter sido "jogadas" no espectro radiofônico e depois disso se viram livres para fazer o tipo de programação e comunicação que julgassem mais oportuna.

\footnotetext{
${ }^{1}$ Vide Tabela 1
} 
O rádio, assim como outras mídias "mais antigas", enfrenta mudanças sociais, tecnológicas, econômicas e políticas. A combinação dessas mudanças fará com que o meio sofra mutações que produzirão efeitos importantes nas emissoras. São estes fatores externos ao meio rádio que causam uma maior preocupação no negócio de rádio, isso porque tais mudanças, na maioria das vezes, escapam de seu controle e, muitas vezes, de sua compreensão. A discussão quase que infindável do modelo de rádio digital no Brasil é um exemplo disso.

TABELA 1: Número de emissoras de rádios no Brasil COMERCIAL

\begin{tabular}{|c|c|c|c|c|c|c|c|c|}
\hline UF & $\mathrm{FM}$ & $O C$ & $\mathrm{OM}$ & от & RTV & TV & TVD & TOTAL GERAL \\
\hline$A C$ & 5 & 0 & 5 & 5 & 75 & 4 & 0 & 94 \\
\hline AL & 17 & 0 & 17 & 0 & 85 & 3 & 0 & 122 \\
\hline AM & 20 & 2 & 20 & 9 & 158 & 5 & 1 & 213 \\
\hline AP & 8 & 0 & 5 & 2 & 18 & 4 & 0 & 37 \\
\hline$B A$ & 92 & 0 & 84 & 1 & 540 & 12 & 0 & 729 \\
\hline $\mathrm{CE}$ & 41 & 0 & 81 & 0 & 230 & 8 & 0 & 360 \\
\hline DF & 17 & 5 & 7 & 0 & 8 & $\theta$ & 0 & 46 \\
\hline ES & 34 & 0 & 18 & 1 & 141 & 7 & 1 & 202 \\
\hline GO & 58 & 3 & 53 & 4 & 304 & 14 & 0 & 436 \\
\hline MA & 20 & 1 & 36 & 3 & 85 & 8 & 0 & 164 \\
\hline MG & 199 & 4 & 174 & 5 & 801 & 18 & 1 & 1303 \\
\hline MS & 28 & 0 & 40 & 4 & 171 & 8 & 1 & 252 \\
\hline MT & 20 & 0 & 43 & 4 & 118 & 8 & 0 & 183 \\
\hline $\mathrm{PA}$ & 29 & 0 & 30 & 8 & 187 & 7 & 0 & 261 \\
\hline PB & 34 & 0 & 33 & 0 & 67 & 7 & 0 & 141 \\
\hline PE & 51 & 0 & 37 & 1 & 85 & 8 & 0 & 183 \\
\hline $\mathrm{PI}$ & 15 & 0 & 46 & 1 & 17 & 4 & 0 & 83 \\
\hline PR & 120 & 10 & 171 & 2 & 297 & 25 & 3 & 628 \\
\hline RJ & 68 & 6 & 59 & 1 & 247 & 13 & 0 & 394 \\
\hline $\mathrm{RN}$ & 15 & 0 & 32 & 0 & 71 & 4 & 0 & 122 \\
\hline RO & 27 & 0 & 16 & 4 & 78 & 6 & 0 & 132 \\
\hline RR & 4 & 0 & 4 & 1 & 31 & 2 & 0 & 42 \\
\hline RS & 165 & 10 & 180 & 0 & 560 & 20 & 0 & 935 \\
\hline SC & 83 & 3 & 103 & 0 & 603 & 16 & 0 & 818 \\
\hline SE & 17 & 0 & 13 & 0 & 43 & 3 & 0 & 76 \\
\hline SP & 281 & 22 & 285 & 15 & 958 & 40 & 14 & 1585 \\
\hline TO & 7 & 0 & 10 & 1 & 88 & 4 & 0 & 111 \\
\hline AL GERAL & 1485 & 66 & 1582 & 72 & 6186 & 270 & 21 & 9682 \\
\hline
\end{tabular}

FM-RADIO EM FREQUENCIA MODULADA OC-RADIOEM ONDAS CURTAS OM-RADIOEMONDASUEDIAS
COMUNITÁRIA

\begin{tabular}{|c|c|}
\hline UF & EMISSORAS \\
\hline$A C$ & 5 \\
\hline$A L$ & 64 \\
\hline AM & 41 \\
\hline AP & 16 \\
\hline$B A$ & 305 \\
\hline CE & 214 \\
\hline DF & 33 \\
\hline ES & 68 \\
\hline GO & 200 \\
\hline MA & 158 \\
\hline MG & 691 \\
\hline MS & 83 \\
\hline MT & 82 \\
\hline PA & 114 \\
\hline PB & 142 \\
\hline $\mathrm{PE}$ & 185 \\
\hline $\mathrm{PI}$ & 78 \\
\hline PR & 287 \\
\hline RJ & 112 \\
\hline RN & 123 \\
\hline RO & 40 \\
\hline RR & 6 \\
\hline RS & 362 \\
\hline SC & 188 \\
\hline SE & 29 \\
\hline SP & 551 \\
\hline TO & 67 \\
\hline TOTAL & 4.242 \\
\hline
\end{tabular}

OT-RADIOEM ONDAS TROPICAIS TV-EMISSORA DE TEIEVSAO TV-EMISSORADE TELEVSAO

\section{EDUCATIVA}

\begin{tabular}{|c|c|c|c|}
\hline UF & FME & TVE & TOTAL GERAL \\
\hline$A C$ & 0 & 0 & 0 \\
\hline AL & 1 & 0 & 1 \\
\hline AM & 0 & 1 & 1 \\
\hline AP & 2 & 0 & 2 \\
\hline$B A$ & 3 & 1 & 4 \\
\hline CE & 8 & 2 & 11 \\
\hline DF & 3 & 1 & 4 \\
\hline ES & 8 & 1 & 8 \\
\hline GO & 5 & 3 & 8 \\
\hline MA & 5 & 1 & 8 \\
\hline MG & 21 & 9 & 30 \\
\hline MS & 4 & 1 & 5 \\
\hline MT & 2 & 0 & 2 \\
\hline $\mathrm{PA}$ & 7 & 2 & $\theta$ \\
\hline PB & 1 & 0 & 1 \\
\hline $\mathrm{PE}$ & 3 & 4 & 7 \\
\hline $\mathrm{PI}$ & 2 & 1 & 3 \\
\hline PR & 10 & 7 & 17 \\
\hline RJ & 5 & 5 & 10 \\
\hline RN & 4 & 2 & 6 \\
\hline Ro & 1 & 0 & 1 \\
\hline $\mathrm{RR}$ & 1 & 0 & 1 \\
\hline RS & 12 & 4 & 16 \\
\hline SC & 8 & 7 & 16 \\
\hline SE & 2 & 1 & 3 \\
\hline $\mathrm{SP}$ & 37 & 17 & 54 \\
\hline TO & 2 & 1 & 3 \\
\hline TAL & 159 & 71 & 230 \\
\hline
\end{tabular}

LEGENDA:

FME-RADIO EDUCATIVA

TVE-TeleVISAO EducATIVA 
No entanto, os fatores internos do rádio são mais importantes. Em linhas gerais, as emissoras de rádio, os radialistas, as empresas e as pessoas que fazem rádio costumam sofrer com um tédio letal do produto, programação, conteúdo e audiência. Prova disso é a falta de criatividade na programação de uma grande parte de emissoras comerciais espalhadas pelo Brasil. Ainda são poucos os que têm interesse de estudar o rádio e seu público. O meio parece estar abandonado de gente criativa ou inventores, fruto, provavelmente, de uma má distribuição do bolo publicitário.

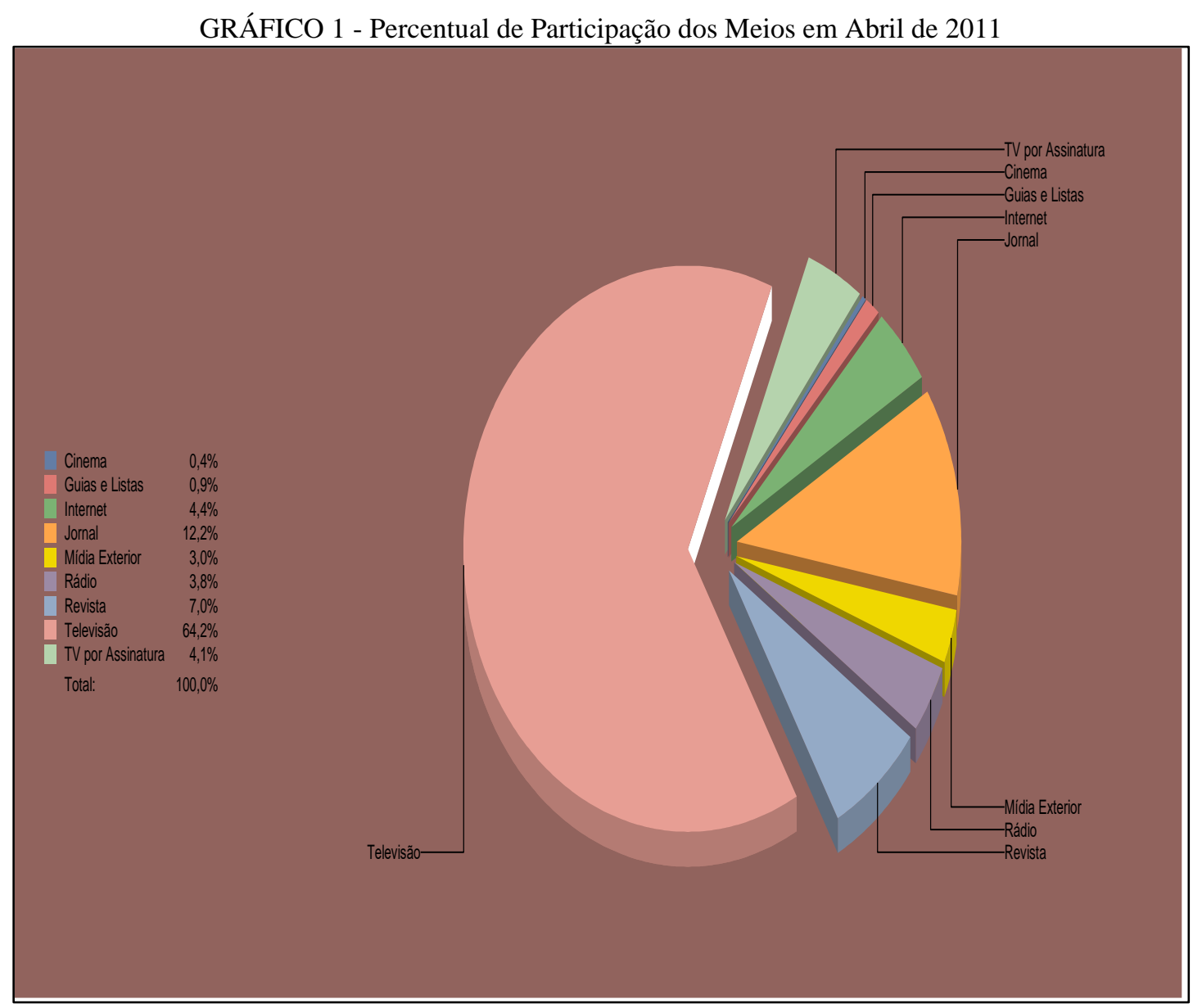

Fonte: http://www.projetointermeios.com.br/ (acessado em 14/05/2011)

O rádio e a mídia, em geral, estão em situação muito mais perigosa devido à fúria e à velocidade com que a inovação técnica se precipita no setor da comunicação, pulverizando as estruturas tradicionais. Algumas ponderações sobre os efeitos determinados pela presença das novas tecnologias podem nos ajudar a enquadrar o nosso momento no mundo da comunicação radiofônica, pois, segundo Bellanger ${ }^{2}$, as novas tecnologias libertam o rádio da escassez de frequências. Esta, por sí só, já é uma mudança radical. A técnica superou esta limitação. Os satélites, a internet e as novas tecnologias se direcionam por novos usos que situam o rádio e outros meios ante um futuro diferente.

\footnotetext{
2 En: BELAU (2001)
} 
A diversificação dos modos de difusão é acompanhada pelo acesso gratuito a vários serviços através de provedores que não exigem qualquer contrapartida econômica para sua subscrição. Muitos dos softwares utilizados para tratamento de música na rede também são gratuitos e de qualidade, como os "player" de qualquer fabricante. Faus Belau (2001) nos diz que o acesso "global à informação ampliou as opções de seleção e abriu horizontes inesperados". A distribuição virtual tem outras consequências: a indústria fonográfica viu como a música se transformou em um código que é distribuído gratuitamente através da rede.

Para John Birt ${ }^{3}$, ex-diretor geral da BBC, a era digital "é caracterizada por uma radiodifusão que precisa colocar na programação uma variedade de serviços que devem estar disponíveis para os ouvintes a qualquer momento". Sem dúvida, novas tecnologias e novos canais de distribuição aumentam significativamente a quantidade e a qualidade dos serviços, conteúdo e distribuição convencionais. Em última análise, um aumento e uma nova concorrência para a mídia de hoje.

Sem esgotar o tema sobre este assunto tecnológico, a conectividade $3 \mathrm{G}$ móvel através de sua conectividade entre os sistemas, permite receber também os serviços de rádio e internet e não são os únicos equipamentos portáteis capazes de alcançar tal êxito.

As novas tecnologias têm um efeito profundo no novo rádio que deverá surgir, transformando processos, descobrindo novas oportunidades e redefinindo mercados. Segundo um estudo da consultoria Spectrum ${ }^{4}$, essa revolução nas comunicações melhorou a comunicação e a qualidade da informação utilizada na produção de informação, resultando numa melhor eficácia da atividade ou de negócios realizados, consequentemente, os consumidores têm uma maior possibilidade de escolha entre um número maior de produtos, serviços, preços e qualidades.

Em termos de rádio, isso significa que a sociedade atual é muito diferente daquela para a qual a "rádio fórmula" ou "vitrolão" foram concebido há algumas décadas, modelo de rádio que ainda hoje fazemos e escutamos. Muitas emissoras vivem como se o tempo tivesse parado.

Existem uma nova sociedade e uma nova linguagem nessa sociedade que não se refletem na mídia em geral e menos ainda no meio rádio. Há uma nova cultura, novas formas e novas maneiras de comunicar; terrenos sem explorar; sonhos inéditos. Este é o momento de investigar, preparar, redefinir, e como diria Faus Belau (2001), "reinventar o rádio".

O rádio é uma questão de intimidade, quase como uma relação passional entre emissor e ouvinte. Ao contrário do que ouvimos hoje, cada dia a narração é mais rígida, mais direta, menos natural. Há muita gente que "fala pela rádio" e muito pouca que faz rádio ao falar.

\footnotetext{
${ }^{3}$ En: BELAU (2001)

${ }^{4}$ En: BELAU (2001)
} 
O rádio perdeu grande parte da capacidade de surpreender, de impulsionar a imaginação, de medir o tempo do relato, inclusive, sua oportunidade de entretecer a realidade e a emoção da palavra, a atualidade e a estética, o essencial informativo, e nós o substituímos pelo monótono bater no mesmo prego durante horas a cada dia da semana. Informações enlatadas da internet, sem o menor critério de seleção. Pois bem, o tempo mudou. O imobilismo comunicacional em uma sociedade dinâmica se paga com a exclusão. Infelizmente, o rádio vem perdendo a capacidade de surpreender, de incentivar a imaginação, de criar histórias e de tecer a realidade e emoção através de palavras.

A relação de dependência do meio e o seu conteúdo em relação à técnica impedem que reinventar o rádio seja uma simples operação de maquiagem, como as levadas a cabo atualmente por algumas emissoras, e principalmente pelas emissoras comunitárias. Trata-se de algo muito mais profundo: a questão não é adaptar, é preciso reinventar desde outra realidade comunicacional, econômica, técnica e social.

Em efeito, a tecnologia criou uma interdependência dos sistemas técnicos informativos de tal natureza que as fronteiras entre alguns meios e outros desaparecerão diluídas na internet.

De acordo com pesquisas realizadas na tese de doutorado de Torres (2007), as rádios comunitárias de maior audiência ou que deram certo em suas comunidades são aquelas que respeitam e conhecem bem os processos históricos, culturais, religiosos e/ou sociais das localidades em que estão inseridas. Nesta situação, é mais importante a formação cultural e intelectual do que radialistas profissionais ou uma infraestrutura técnica de ponta.

Sendo assim, a realidade e o sentido de "sucesso" de uma rádio comunitária não seguem os mesmo parâmetros de uma rádio comercial, que, normalmente, são medidos com referência aos parâmetros econômicos e/ou audiência. No momento em que isso ocorre, o êxito da rádio não depende da inteligência dos profissionais, nem da competência da equipe, nem sequer da qualidade do produto, mas sim de toda uma série de fatores aleatórios derivados da dinâmica tecno-mercantil (ou política, em seu caso), que pouco ou nada têm que ver com a comunicação.

A tecnologia permite hoje a pequenas emissoras empreender negócios próprios das grandes empresas tradicionais. De fato, a tecnologia atual tende a facilitar à empresa radiofónica local na sua reconversão em uma empresa internacional, sem custos econômicos adicionais notáveis. Sendo assim, o panorama da comunicação está mudando radicalmente. O que até hoje chamamos meios, serão substituídos por uma multidão de canais ou aparatos de distribuição. Neste contexto, a qualidade do produto informativo será decisiva. Nesta dinâmica, os “programas" já não podem ser concebidos para um só meio de distribuição: a distribuição alternativa deve ser tomada em consideração da fase de planejamento da produção de programas. Estamos ante a fissão midiática que dará passo a outra época da comunicação. 
Entretanto, a utilização dos meios tradicionais de comunicação de massa nem sempre se apresentam como meio acessível para a difusão das necessidades e reivindicações dos setores mais empobrecidos ou vulneráveis da sociedade. Neste sentido, os meios comunitários de comunicação e difusão vêm insistindo, faz tempo, para incluir na pauta nacional estratégias e conteúdos que atendam às necessidades destas comunidades.

Dito isso, o Relatório Anual da Relatoria para a Liberdade de Expressão 2002 faz uma valiosa referência a este tema quando diz que:

\begin{abstract}
“As rádios chamadas comunitárias, educativas, participativas, rurais, insurgentes, interativas, alternativas e cidadãs são, em muitos casos, e quando atuam no marco da legalidade, as que ocupam os espaços deixados pelos meios de comunicação de massa; se erguem como meios que canalizam a expressão onde os integrantes de setores empobrecidos da população nunca teriam voz ou participação nos veículos tradicionais" (CIDH, 2002, P.65).
\end{abstract}

Ou seja, não há dúvida de que a liberdade de expressão é boa e muito importante para o desenvolvimento de uma nação e principalmente das comunidades, mas isso deve ser feito de uma maneira organizada, assim como bem diz neste relatório: "no marco da legalidade". E para não ter dúvidas sobre o tema, o relatório continua:

\begin{abstract}
“As rádios comunitárias, que devem atuar no marco de legalidade facilitado pelos Estados, respondem em muitos casos às necessidades, interesses, problemas e expectativas de setores muitas vezes relegados, discriminados e empobrecidos da sociedade civil. A necessidade crescente de expressão das maiorias e minorias sem acesso aos meios de comunicação e sua reivindicação do direito de comunicação, de livre expressão de ideias e de difusão de informação tornam imperativa a necessidade de procurar bens e serviços que lhes assegurem condições básicas de dignidade, segurança, subsistência e desenvolvimento. Em muitos casos, estas emissoras podem, atuando dentro do marco da legalidade, facilitar a circulação livre de informação, respirando a liberdade de expressão e o diálogo dentro das comunidades para promover a participação" (CIDH, 2002, P.65).
\end{abstract}

Requillo (2001) assinala-nos que o acesso equitativo, digno e imaginativo aos meios como síntese contemporânea do público é uma maneira fundamental de romper a leitura "individualizada" e insular da pobreza, a condição de superar essa visão que assume que mais meios, mais notícias ou programas sobre pobreza e pobres e mais crônicas (desde fora) constituem realmente o fortalecimento dos setores marginais de cara a uma comunicação democrática.

Dada a importância que podem ter estes canais de exercício da liberdade de expressão comunitária, resulta inadmissível que as rádios comunitárias que tenham licença para funcionar façam um uso não criativo desta licença e simplesmente operem de acordo com a "rádio fórmula", ou seja, de acordo com as milhares de emissoras comerciais já existentes, não fazendo nada diferente do habitual. 
Entendemos que os estados em sua função de administradores das ondas do espectro radioelétrico devem distribuí-las de acordo com critérios democráticos que garantam uma igualdade de oportunidades a todos os indivíduos. Mas somente isso não basta, é preciso também fazer uma verificação e comprovar se estas emissoras comunitárias realmente estão funcionando de acordo com a lei que as regulamenta e se realmente estão levando algo novo à comunidade que lhe compete, para não transformar este importante meio em um "mass media" a mais.

A atual mudança deve ser uma mudança radical. A rádio, seja comunitária ou não, precisa ser criativa, inovadora e flexível para conduzir as mudanças no momento atual.

Um dos objetivos da tese de doutorado de Torres (2007) foi tentar identificar por que estas emissoras, que tanto lutaram para obter uma lei e depois uma licença para operar, insistam, em sua maioria, em não apresentar nenhuma proposta nova de fazer rádio. Sendo assim, tentamos identificar os principais problemas que uma rádio comunitária encontraria hoje para manter seu funcionamento.

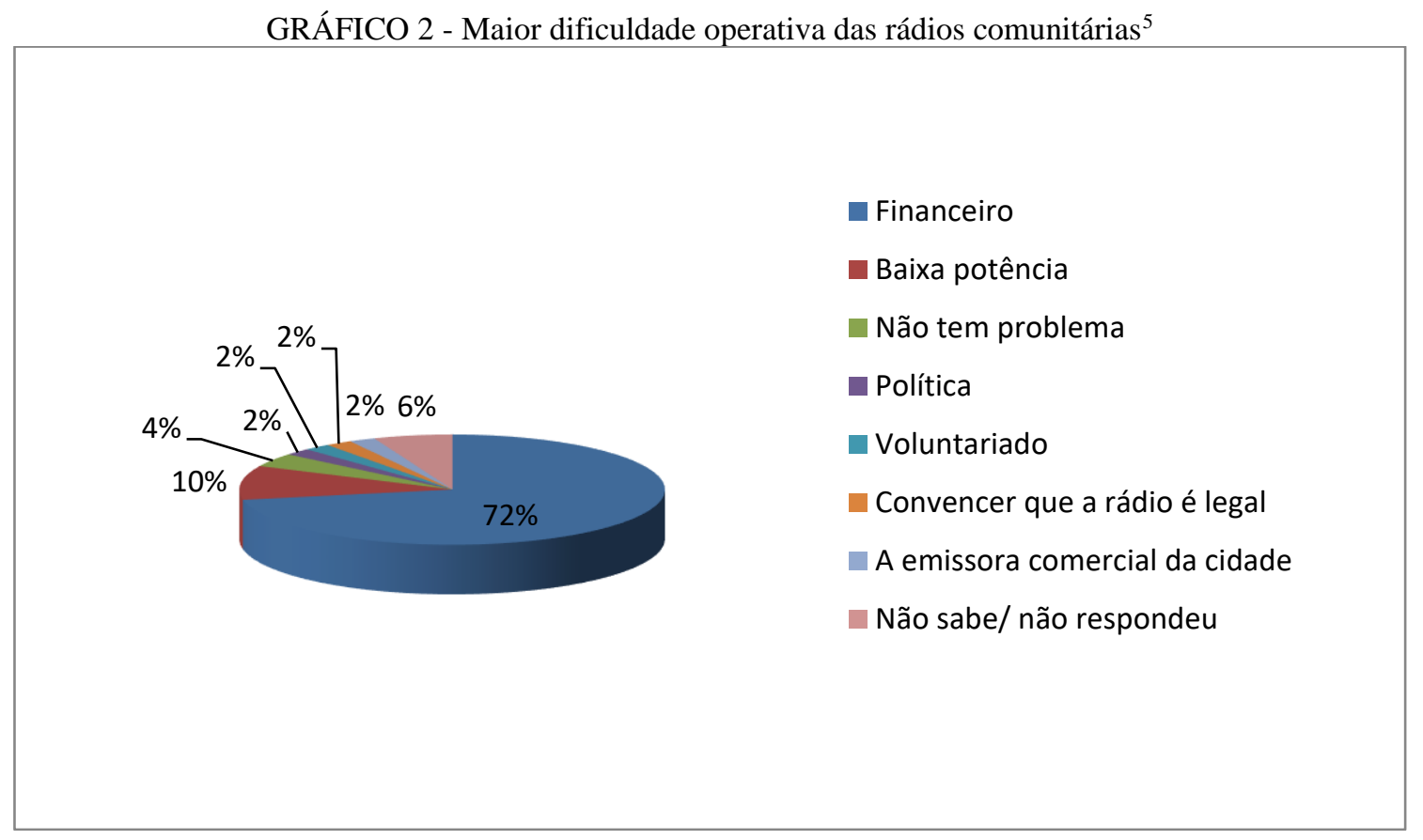

A questão financeira é sem dúvida o grande problema para a maioria das rádios comunitárias, $76 \%$ das emissoras disseram que manter as contas em dia é uma tarefa muito difícil. Seria um pouco mais complicado tentar identificar o ponto principal desta questão financeira, mas como fui o único entrevistador da pesquisa, pude notar que os maiores problemas variam entre pagar as contas como a de água e principalmente a de luz, que é mais cara por causa dos equipamentos eletrônicos que devem permanecer ligados durante muito tempo; problemas também com as taxas e impostos que as emissoras

\footnotetext{
${ }^{5}$ TORRES, 2007, p.437.
} 
têm que manter em dia, tais como a taxa do ECAD, que muitas rádios confessaram não pagar, muitas vezes por realmente não terem condições ou por acreditarem que a taxa é abusiva. Outro problema relatado informalmente pelos entrevistados na questão financeira é vender os apoios culturais necessários para pagar o custo da emissora. Os radiodifusores dizem que os apoios culturais são vendidos a preços muito baixos devido ao alcance da emissora que normalmente é muito pequeno. $\mathrm{E}$ sobre os apoios culturais, os entrevistados disseram que é difícil criar esses apoios dentro da lei ${ }^{6}$, já que ela não permite fazer uma série de coisas, como divulgar preços de produtos, por exemplo. Para Ruas (2004, p. 13), o apoio cultural "significa apenas citação do nome da empresa que patrocina o espaço. Assim elas podem admitir patrocínio, mas sob a forma de apoio, e os estabelecimentos que o fazem devem, obrigatoriamente, situar-se na área da comunidade atendida”.

Apenas $10 \%$ das rádios comunitárias disseram ser a potência o principal problema da emissora e $4 \%$ declararam que a emissora não tem nenhum problema de funcionamento. Esses sim são muito felizes e poderiam, possivelmente, informar aos outros companheiros radiodifusores comunitários como se faz para não ter nenhum problema.

A comunicação é um dos elementos formadores da sociedade desde o momento em que influi na construção da personalidade do indivíduo, em suas ações, seu comportamento e, consequentemente, nas atitudes coletivas. Cria, além do caráter singular, um caráter social coletivo.

\footnotetext{
“A sociedade existe na comunicação e por meio da comunicação, porque é através do uso de símbolos significativos que nos apropriamos das atitudes dos outros, assim como eles, a seu tempo, apropriam-se de nossas atitudes. Isto quer dizer que a personalidade é um produto social, gerada graças à interação com as demais pessoas. Em outras palavras, a comunicação tem a função de gerar identidade" (BORDENAVE, 1986, p. 27).
}

Para a investigadora Ruas (2004, p. 141), é inquestionável a influência exercida por meios de comunicação no cotidiano da sociedade. Os meios de comunicação têm a capacidade de alcançar o público, persuadi-lo e até atribuir simpatia ou repulsa a feitos ou a indivíduos, de acordo com sua conveniência. Embora tendo consciência disso, a sociedade, de modo geral, não sobrevive sem dispor de seus serviços.

Segundo Bordenave (1986, p. 91), os meios de comunicação vão tornar-se, então, “instrumentos para a identificação de assuntos que necessitam atenção em nossa sociedade, articulando genuínas preocupações do povo, particularmente dos sub-privilegiados na sociedade, somando tais necessidades de decisão e realimentando com esta demanda os níveis de ação diretiva".

Essa instrumentalização de meios para a identificação que a sociedade quer e necessita pode ser observada pelo surgimento da comunicação comunitária, sendo uma forma encontrada de

${ }^{6}$ BRASIL. Lei n.o 9.612, de 19 de fev. 1998. Institui o Serviço de Radiodifusão Comunitária. Diário Oficial, Brasília, 20 fev.1998. 
aproximar a emissão da recepção nos dois sentidos. O primeiro em forma física, aproximando os dois, veículo e público, continuando pela apropriação do conteúdo, que passa a ser de interesse local, como nos conta Ruas (2004, p. 140), dizendo que "o local vem tomando uma grande importância no contexto global". Encontrando força no fenômeno histórico vivido, a globalização, que nos leva também à globalização das comunicações, procurou formas criativas de revelar o local, através da segmentação. Rosa (1998, p. 12) diz-nos que "a rádio passa pela segmentação, pois cada emissora possui uma determinada linguagem, perfil de público e estilo de programação, e cada vez menos veremos uma rádio alcançando grandes massas e cada vez mais rádios atuando por nichos de mercado".

Sobre este tema, Ruas (2004, p. 56) acrescenta que a comunicação, por meio dos veículos de comunicação, deve compreender que pôr esforços para investigar ou alterar a realidade social brasileira não é mais uma questão de opção, "mas sim um imperativo para a sobrevivência do país. Para que o Brasil possa competir economicamente com os países avançados, os indivíduos devem aprender a aprender: condição indispensável para acompanhar as mudanças e avanços cada vez mais rápidos".

Neste contexto, Pascoal (2001, p. 9), apropriadamente, afirmou que "o papel dos meios de comunicação é informar, ajudando a sociedade a conhecer, pensar e atuar. A educação, portanto, é diretamente uma característica dos meios de comunicação". Ainda segundo o autor, um povo somente pode ser grande se sua educação for boa e se os meios de comunicação forem livres, plurais e responsáveis.

"El reto actual de la radio es hacer frente al nuevo entorno multimediático, como tuvo que hacerlo cuando apareció la televisión y la audiencia se entregó al nuevo medio. Fue justo durante esta crisis cuando la radio consiguió una transformación a fondo en dos orientaciones: técnica y creativa." (HERREROS, 2001, p 143)

Em uma sociedade cuja realidade está altamente centralizada e informatizada, onde os meios privados e públicos de comunicação são poder e estão a serviço do poder, as rádios comunitárias surgem ante a necessidade e o direito de toda pessoa individual ou coletiva de expressar livremente opiniões, criticar e oferecer alternativas em tudo àquilo que lhes afete direta ou indiretamente.

Diante de todo exposto, faz-se necessário estudar as rádios comunitárias porque, como bem disse José Vigil, em sua obra "Manual urgente para radiofonistas apasionados", elas "não se submetem a lógica do dinheiro nem da propaganda. Sua finalidade é diferente, suas energias estão colocadas a serviço da sociedade civil. Um serviço altamente político: se trata de influenciar a opinião pública, de criar consenso, ampliar a democracia". E em definitivo, inclusive pelo seu nome, as rádios comunitárias deveriam ter a obrigação de construir novas comunidades e transformar realidades. Resta saber se essas rádios comunitárias operantes em nosso país estão conscientes de sua responsabilidade 
diante da sociedade e se seus comunicadores estão preparados para fazer cargo de tal responsabilidade: comunicar-se através de um meio de comunicação de massa e fazer rádio de uma maneira diferente. 


\section{REFERÊNCIAS}

BELAU, F.A. Reinventar la Radio. Chasqui N74. Quito, CIESPAL: 2001.

BORDENAVE, J. E. D. O que é comunicação. São Paulo: Nova Cultura-Brasiliense, 1986.

BRASIL. Lei n. ${ }^{\circ}$ 9.612, de 19 de fev. 1998. Institui o Serviço de Radiodifusão Comunitária. Diário Oficial, Brasília, 20 fev.1998.

HERREROS, M. C. Información Radiofónica. Mediación técnica, tratamiento y programación. Madrid: Editorial Síntesis, 2001.

Informe de la Relatoría Especial para la Libertad de Expresión, CIDH,.Informe anual, ano 2001.

PASCOAL, N. L. Educação, voluntariado e mídia. São Paulo: Fundação Educar Dpaschoal, 2001.

ROSA, A. N. Atração global: a convergência da mídia e tecnologias. São Paulo: Makron Books, 1998.

RUAS, C. M. s. Rádio comunitária: uma estratégia para o desenvolvimento local. Campo Grande: UCDB, 2004.

TORRES, Bruno Araujo. Voces radiofonicas: las radios comunitárias em Brasil. Disponível em: http://www.tdx.cat/TDX-0801108-120655 Valencia, Universitat de Valencia: 2007.

UNESCO: World Communication Report 1998. In CIDH, Informe Anual, ano 2002, Informe de la Relatoría Especial para la Libertad de Expresión.

VIGIL, J. I. L. Manual Urgente para radialistas apaixonados. São Paulo: Paulinas, 2003. 